\title{
A simple apparatus to assess cutaneous thermal sensitivity
}

\author{
MARGARET F BRUCE \\ From the Department of Anatomy, University of Aberdeen, Scotland
}

SUMMARY A simple contact stimulator designed to provide quantitative assessments of thermal sensitivity of digital skin is described. The skin is tested at its normal resting temperature and thermal thresholds are given as the least differences in temperature between the skin and the stimulator which give rise to warm or cool sensations.

Apparatus designed to assess cutaneous sensory performance should mirror the kind of stimulation which is encountered in everyday situations. The skin site to be tested should be on the hands, preferably on the fingers; the site will determine the size of the stimulators which in turn should have thermal properties such that an appropriate range of stimuli can be produced. The test procedure should present the subject with a simple, familiar and not too demanding task. His performance should be assessed under normal physiological conditions; in particular, his skin temperature should be that to which he has become acclimatised in the test room. The apparatus described is simple to construct and to use, and enables a rapid quantitative assessment of thermal sensory performance to be included in a neurological examination.

\section{Method}

The skin site is brought into contact with a series of stimulators consisting of identical flat topped brass screws inserted into a solid brass rod (fig). A temperature gradient $\left(15^{\circ} \mathrm{C}-45^{\circ} \mathrm{C}\right)$ is created and maintained along the bar and thus along the stimulators, by screwing one end of the bar into a solid brass cylinder which is heated by means of a length of heating tape wound round the cylinder. Between the tape and the cylinder a thermosensor connected to a thermostat (set at $60^{\circ} \mathrm{C}$ ) is inserted and the heating assembly is then insulated. The opposite end of the bar is inserted into a cooling assembly consisting of an insulated box filled with

Address for reprint requests: Dr Margaret F. Bruce, Department of Anatomy, Marischal College, Aberdeen AB9 1AS, Scotland.

Received 16 October 1981 and in revised form 8 January 19.82 Accepted 30 January 1982 an ice and salt mixture. The bar, supported on a sliding platform, can be moved along a fixed base so that any stimulator can be brought into position above the finger being tested. The finger, cradled in modelling clay, is supported on a moveable platform which can be raised, lowered or moved at right angles to the direction of the movement of the bar. The finger is raised until the subject reports that firm contact has been made with a stimulator. An adjustable stop is moved into place so that in all subsequent stimulations the finger is raised to that level, thus the mechanical component of the stimulation remains constant while only the thermal component is varied.

The subject is instructed to give one of the following responses when contact is made-cool, neutral or warm. No equivocal responses are allowed. Neutral is the response to be given when the subject perceives no identifiable thermal sensation following stimulation. Each subject is given a trial run in which different stimulators representing the range of stimuli are presented in random order so that he may become familiar with the procedure. The apparatus is screened from the subject throughout the test.

The temperature of the skin and of the stimulators is recorded throughout using two suitable thermoprobes, each attached to a skin thermometer. Testing commences only when the skin temperature has become stabilised. The first stimulator to be applied is that nearest in temperature to the skin temperature. The test sequence starts when the temperatures of the site and of the stimulator are taken immediately prior to the first stimulation; the stimulus is applied for five seconds and the subject's response noted; the finger is lowered and "rested" for 20 seconds. The next stimulator is slid into place; the temperature of the skin and of this stimulator are noted and the finger is raised to make contact again. This sequence is continued until a change of response is obtained and then is continued for one more stimulation in order to confirm that change. If the response is consistent the sequence is reversed until the original response is obtained and confirmed. If the first response is neutral and if the stimulators are introduced in order of increasing tempera- 


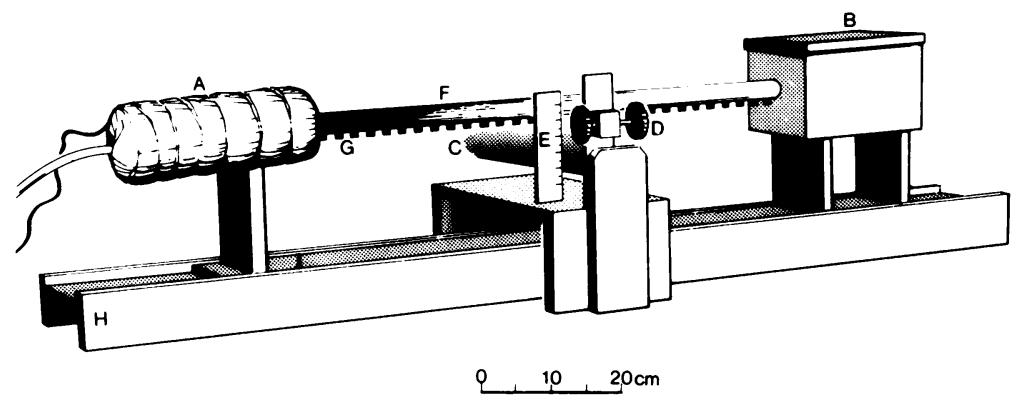

Figure The heating assembly $(A)$ and the cooling assembly $(B)$ are inserted into opposite ends of a brass bar $(F)$. Each assembly is independently supported on vertical uprights which are fixed to a sliding platform (I) which can be moved along the length of the fixed base $(H)$. Into the bar are screwed a series of identical stimulators $(G)$. The finger is cradled in modelling clay on the support platform $(C)$ which can be raised or lowered by means of the rack and pinion (D). E is a vertical scale carrying a stop which is moved into position when firm contact between finger and stimulator is made, so that the finger is raised to that level for all subsequent stimulations. The finger support is mounted on a bridge which can be moved at right angles to the base so that the specified test site can be brought directly under the stimulator.

ture, the following sequence is obtained: neutral $\rightarrow$ warm: warm $\rightarrow$ neutral. After a 30 second pause the test is repeated in the opposite direction producing the sequence: neutral $\rightarrow$ cool: cool $\rightarrow$ neutral.

The value taken to indicate the level of sensory performance is the difference in temperature between skin and stimulator which gives rise to a sensation of warmth (or of coolness). The mean of the two minimum differences obtained in the test sequence neutral $\rightarrow$ warm: warm $\rightarrow$ neutral represents the threshold for warmth and the cool threshold is found in the same way. The sensory thresholds can be expressed thus:

$$
S_{W}=\frac{D_{W 1}+D_{W 2}}{2} \text { and } S_{C}=\frac{D_{C 1}+D_{C 2}}{2}
$$

where $S_{W}$ and $S_{C}$ are the thresholds for warm and cool respectively. $D_{W 1}$ and $D_{C 1}$ are the least differences in temperature between skin and stimulator required to produce a sensation of warmth or cool respectively in the first half of a test sequence and $\mathrm{D}_{\mathrm{W} 2}$ and $\mathrm{D}_{\mathrm{C} 2}$ corresponding differences in the second half.

\section{Discussion}

The apparatus and the procedure described here offer several important advantages over other thermal sensory testing devices. ${ }^{1-8}$ Dyck et al $^{6}{ }^{7}$ used thermodes of different materials so that each has a different thermal capacity. Thus thermal judgements are made against different background "noise" generated by the varying non-thermal stimulation resulting from differences in material. The stimulators described here are of the same material, applied with the same mechani- cal pressure, and differ from each other only in temperature.

The low conductivity of some of the Dyck stimulators means that the size of the stimulators must be fairly large, so precluding their use on the digits where the loss of sensory capacity has the most profound effects. In addition, the decision-making task faced by the subject here, where each response is independent of the others, is much simpler than in the Dyck test where stimuli are presented successively in pairs and the subject is required to "carry" a memory of the first stimulus against which to compare the second.

The Kenshalo group ${ }^{3}$ used apparatus based on the Peltier principle which restricts the nature of the stimulation to that providing a rate of change of only some $2^{\circ} \mathrm{C}$ per second, whereas thermal stimuli should have rates of change greater than $5^{\circ} \mathrm{C}$ per second if they are to approach the conditions obtaining in daily experience, such as when a metal surface is touched. ${ }^{8}$ In other studies ${ }^{158}$ the skin site is first brought to some arbitrary predetermined "adapting" temperature ${ }^{5}$ maintained by a thermode in constant contact with the skin. Two major disadvantages follow from this practice. (a) The range of individual variation in the temperature of the extremities is considerable-from $20^{\circ} \mathrm{C}$ to $35^{\circ} \mathrm{C} .{ }^{910}$ To bring one subject to an adapting temperature of, for example $30^{\circ} \mathrm{C}$ may require that his skin be maintained at a temperature some $10^{\circ} \mathrm{C}$ above his normal level while for another it may require that his skin temperature be lowered by some $5^{\circ} \mathrm{C}$. Under such conditions it is unlikely that a meaningful estimate of everyday sensory capacity is obtained. (b) 
Only the small area of skin in contact with the thermode is maintained at the predetermined temperature while the surrounding skin may be at a temperature considerably different from this, so that complex and conflicting information about the physiological state of the skin will be received centrally, forming a confused background to the thermal input from the test site.

Finally, for practical purposes it is possible to disregard both the normally-occurring minor fluctuations in skin temperature and also the small fluctuations in stimulator temperature ${ }^{10}$ which occur within and between tests, thus eliminating the need for expensive feed-back control devices. ${ }^{158}$

The apparatus and the procedure described here can be used to provide, quickly and relatively inexpensively, quantified estimates of sensory performance which will facilitate comparison of past with present performance as well as between levels of performance in different sites on the body.

\section{References}

1 Hilder R, Ramey E, Darian-Smith I, Johnson KO, Dally LJ. A contact stimulator for the study of cutaneous thermal sensibility. J App Physiol 1974;37:252-5.

${ }^{2}$ Hensel H, Zotterman Y. Action potentials of cold fibres and intracutaneous temperature gradient. $J$ Neurophysiol 1951;36:377-85.

${ }^{3}$ Kenshalo DR, Bergen DC. A device to measure cutaneous temperature sensitivity in humans and subhuman species. J App Physiol 1975;39:1038-140.

${ }^{4}$ LaMotte RH, Campbell JN. Comparison of responses of warm and nociceptive C-fibre afferents in monkey with human judgements of thermal pain. $J$ Neurophysiol 1978;41:509-28.

${ }^{5}$ Morrow TJ, Casey KL. A contact thermal stimulator for neurobehavioural research on temperature sensation. Br Res Bull 1981;6:281-4.

${ }^{6}$ Dyck PJ, Curtis DJ, Bushek W, Offord K. Description of "Minnesota Thermal Disks" and normal values of cutaneous thermal discrimination in man. Neurology (Minneap) 1974;24:325-30.

' Dyck PJ, Zimmerman IR, O'Brien PC, Ness A, Caskey $\mathrm{PE}, \mathrm{Karnes} \mathrm{J}$ et al. Introduction of automated systems to evaluate touch-pressure, vibration and thermal cutaneous sensation in man. Ann Neurol 1978;4:501-10.

${ }^{8}$ Darian-Smith I, Dykes RW. Peripheral neural mechanisms of thermal sensation. In: Dubner R, ed. Oro-facial Motor Mechanisms. New York: Appleton-CenturyCrofts, 1971:7-21.

${ }^{9}$ Lele PP, Weddell G, Williams CM. The relationship between heat transfer, skin temperature and cutaneous sensibility. J Physiol (London) 1954;126:206-34.

${ }^{10}$ Bruce MF. Psychophysiological and peripheral morphological aspects of touch and temperature sensibility. $\mathrm{PhD}$ thesis, Univ. of Aberdeen, 1980. 